\title{
Dimensions of User Experience - from the Product Design Perspective
}

\author{
KERSTIN BONGARD-BLANCHY \\ CAROLE BOUCHARD
}

Arts et Métiers ParisTech

Résumé : Le domaine EU (Expérience Utilisateur) a été étroitement lié au développement des logiciels. Les méthodes UX trouvent cependant de plus en plus d'applications dans le Design de Produits. Aujourd'hui le Designer Produit doit mettre en œuvre des compétences qui vont bien au-delà de la seule définition de l'apparence. L'objet de cet article est de mettre en lumière ces dimensions du design que les Designers Produit soucieux de concevoir dans le respect de l'UX ne sauraient ignorer. L'article apporte ainsi une vue globale sur les dimensions susceptibles d'impacter l'UX. L'identification des dimensions pertinentes puise à la fois dans les théories de la psychologie cognitive, dans les modèles d'interaction homme-machine, ainsi que dans les résultats de la recherche en design. Ces dimensions sont ensuite regroupées sous quatre catégories : les dimensions de la perception humaine, du produit et du contexte de l'utilisation, ainsi que la dimension temporelle. Enfin, ces dimensions sont mises en relation dans un schéma qui illustre le cours de l'expérience entre un utilisateur et un produit, dans un contexte et avec sa temporalité.

Mots clés : Design Produit, dimension UX, produit interactif, design conceptuel, interaction utilisateur-produit

Abstract: The UX domain has so far been strongly associated with software development. However, its methods are finding their way into domains like Product and Service Design. Product Designers now need competencies far beyond classical form-giving. The objective of this paper is to show Product Designers which design dimensions they need to attend to when designing for UX. The paper gives an overview of design dimensions that potentially impact how users' experience products. These dimensions are brought together from theories of Cognitive Science, models of Human-Computer Interaction and findings from Design Research. They are presented under four categories: dimensions of human perception, dimensions of products, dimensions of the context of use and the temporal dimension. In the final part, the identified dimensions are connected into a schema, illustrating their interplay and therefore the journey of UX between a user and a product, in a certain context over a certain time.

Key words: Product Design, UX dimension, interactive product, conceptual design, user-product interaction.

Adresse des auteurs : Kerstin Bongard-Blanchy (kerstin.blanchy@gmail.com), Carole Bouchard (carole.bouchard@ensam.eu) LCPI, Arts et Métiers ParisTech, 151 boulevard de l'hôpital, 75013 Paris, France.

Les articles de JIPS sont publiés sous licence Creative Commons Paternité 2.0 Générique. 


\section{Introduction}

Do you remember the first TV sets of the 1960's? They were based on analogue technology and had a single functionality. Now look at the latest devices presented at tech fairs such as CES (International Consumer Electronics Show). Today, TV is digital and "smart". The devices are multifunctional. You can access content anytime, get additional information and comment on content via social media. With the arrival of the Internet of Objects the consumer can now personalize more and more products to his/her needs and desires. As a consequence, the role of the Product Designer has gained complexity far beyond form-giving. Today s/he has to design for an experience for the user.

UX (User Experience) has become a topic of interest for researchers and companies even outside its traditional domains. As can be seen in

Figure 1, researchers in cognitive psychology were the first to look at the human perception of objects (Gibson 1986). With the arrival of personal computers, the domain of Human-Computer Interaction emerged as a means to improve the usability of graphical interfaces (Forlizzi and Ford 2000). In the Product Design domain, the study of human factors gained importance for the same objective: that of optimizing usability (Norman 1988; Green and Jordan 1999). Researchers of "Kansei Engineering" (Tomico et al. 2008) in Asia were the first to anticipate the emotions, sensations and semantics conveyed by a Product Design.

In the Western world, the start of the new century saw the advent of research into "Emotional Design"; the study of the emotional value of products (Desmet 2002; Norman 2004). Furthermore researchers of "Affective Engineering" investigate the sensorial experience evoked by materials and textures (Salvia et al. 2010).

While UX is still commonly associated with the realm of Human-Computer Interaction, other domains such as Product or Service Design integrate the findings of these various domains under the paradigm of UX Design / Experience Design (Hassenzahl 2011).

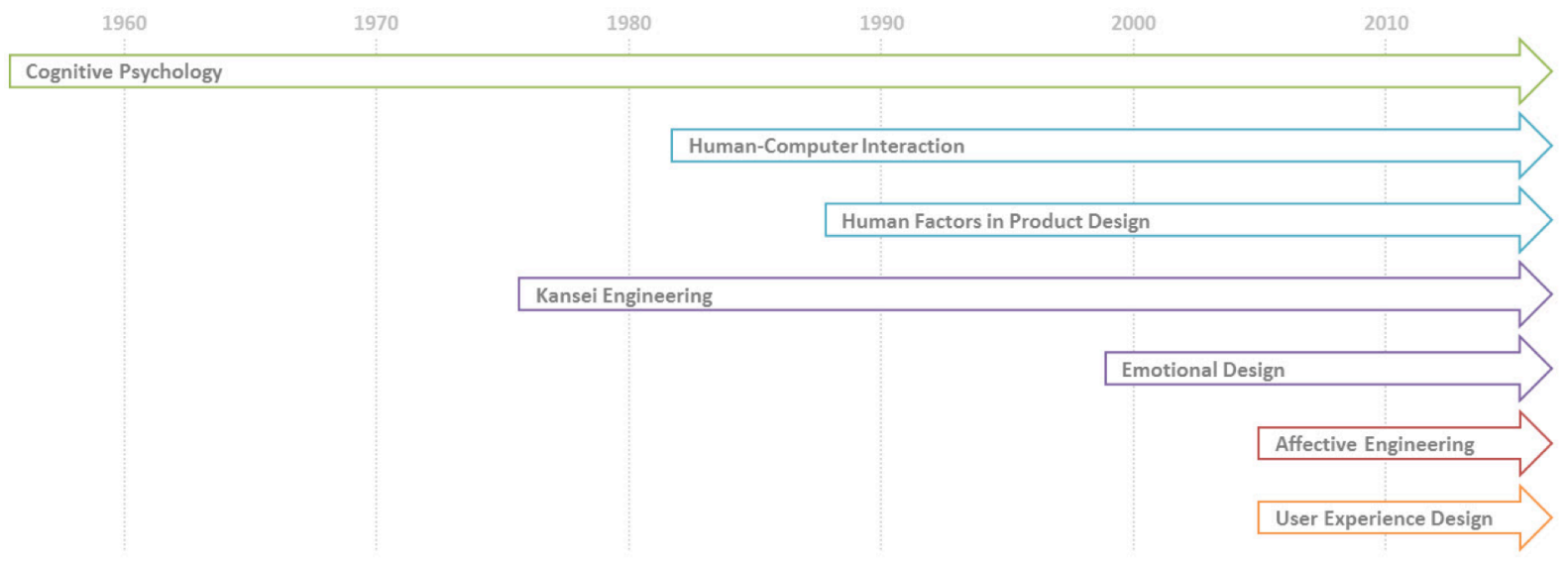

Figure 1: Evolution of research domains related to the UX of Products.

Designing for and researching UX require the consideration of a multitude of dimensions (Robert and Lesage 2011). A review of studied dimensions in UX related papers revealed an array of UX dimensions including affect/emotion, enjoyment/fun, aesthetics/appeal, hedonic quality, engagement/flow, motivation, enchantment and frustration (Bargas-Avila and Hornbæk 2011). This disparate list demonstrates the inconsistencies that remain in the classification of UX dimensions.

UX is defined as "a person's perceptions and responses that result from the use or anticipated use of a product, system or service" (ISO 9241-210). In this definition appear the human and the product with their respective perceptive and responsive capabilities. These capabilities can be addressed by Product and Interaction Design (Djajadiningrat et al. 2004). In this paper we seek to consolidate the insights from the afore mentioned research domains. We look at dimensions that influence the user's perception and then define the range of product dimensions that can evoke a specific reaction of the user. The context of use and the temporality of experience are added as third and fourth layer. Together they lead us towards a schema of UX in Product Design. 


\section{BASICS OF USER-PRODUCT INTERACTION}

The manner in which users experience products is similar to how humans perceive their environment and the objects within it - the mechanisms that humans employ to do this have been investigated by Cognitive Psychology, Neuroscience, Sociology, Semiotics, and Philosophy for many decades.

The human nervous system interacts with the environment through sensory inputs and motor outputs. Organisms use sensors to capture changes of the environment in order to anticipate and coordinate actions that help them to fulfil their goals (e.g. nutrition, reproduction, and belonging). These sensors constantly adapt their state upon interaction with the environment or object. Humans do not perceive characteristics of the environment but rather opportunities for action, so called affordances, like climb-ability, pull-ability, etc. (Gibson 1986). When people perceive their surroundings they recognise coherent patterns of objects or events that have a meaning to them (Russell 2003). For UX design this means visual properties like form or colour do not become stimuli just by themselves but through the affordance they communicate.

The path that sensory input takes inside the nervous system can be modelled as 'perception loops'. Either the input is treated quickly and leads to a direct response - treatment on 'system 1' level- or it enters a more profound treatment of measurement, computation, prediction, evaluation - the so-called 'system 2'. In the latter case, sensed patterns are compared to previous patterns and knowledge templates are continually created or altered (Axelrod 1973; Cariani 2001; Kahneman 2011).

The nervous system determines which actions to take in response to the sensed input. The action organs (e.g. muscles) respond and potentially alter the state of the environment or the object they interact with. This leads to new sensory inputs for the human. The human learns to understand an unfamiliar object by interacting with it (Russell 2003) because perception is based on successive reception and actions (Lenay 2006).

The course of these interaction sequences between the human and the product are furthermore influenced by the context in which they happen and by previous experiences the human had with this environment or object.

Various researchers in the UX domain have proposed schemas that illustrate the interplay of dimensions that form the UX. Among them are Forlizzi and Ford's (2000) 'Initial framework of experience', Hassenzahl's (2003) 'Model of User Experience', Crilly et al.'s (2004) 'Framework for consumer response to the visual domain in product design', Krippendorff's (2005) 'Interaction protocol of an interface', Schifferstein and Hekkert's (2008) 'Model of human-product interaction' and Locher et al.'s (2009) 'Framework for aesthetic interaction', and Robert and Lesage's (2011) 'The inputs and outputs of UX'. Each schema looks at UX from its particular point of view. Together, they give an overview on the multitude of dimensions that constitute UX and that should play a part in early Product Design and Product Design evaluation. In the following, we will try to consolidate the various dimensions inside one schema and give detailed descriptions for each dimension. The dimensions are organised and presented under the four categories (see Figure 2):

1. Dimensions of Human Perception / the User

2. Dimensions of Products

3. Dimensions of the Context of Use

4. The Temporal Dimension of UX
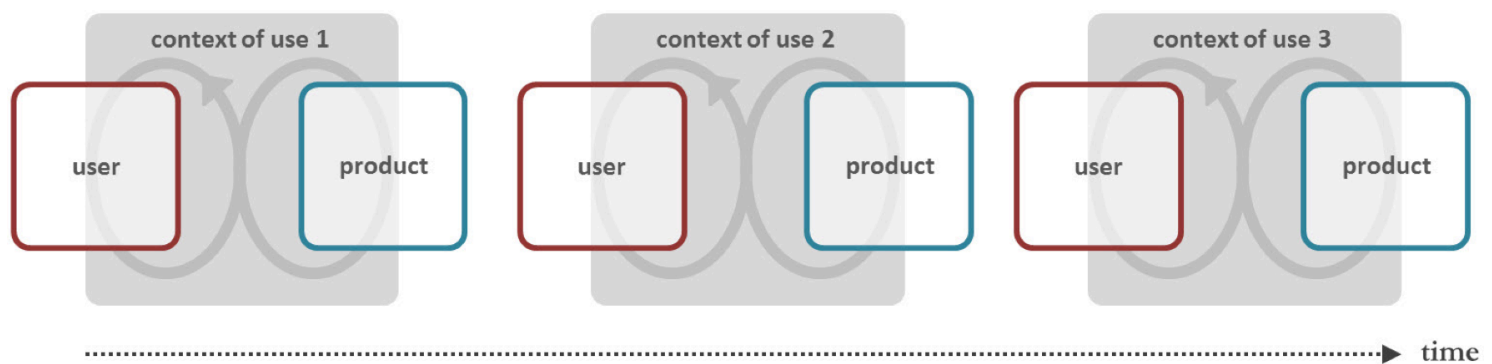

Figure 2: The dimensions of UX are presented under four categories: user, product, context of use and time. 


\section{DIMENSIONS OF HUMAN PERCEPTION}

A user is a person who is targeted to utilise a product. S/he approaches the product with a specific extrinsic goal - what do I consciously expect from this product? - and intrinsic expectations that have been formed by former experiences in addition to his/her personal living conditions (Robert, Lesage 2011). The dimensions that define the user profile are the person's age and gender (Crilly, Moultrie, and Clarkson 2004), cultural background, living environment (Locher, Overbeeke, and Wensveen 2009), education, occupation and interests.

The user encounters a product. Neuroscientists do not yet agree on the brain mechanism involved (Cariani 2001; Bonnardel 2012) in the human perception of objects. What is known is that sensing, cognition and affect, and response are embedded in neural discharge activities. In the following we look at dimensions of these three steps of human perception: human sensors, human cognition and affect, and human responses.

\section{HUMAN SENSORS}

In order to perceive their surroundings, humans dispose of a limited range of physiological sensors. They can be classified into exteroceptive, proprioceptive, interoceptive sensors and chronoception (LaMuth 2011). Table 1 gives an overview and definition of each type of human sensor.

Table 1: Types of human sensors.

\begin{tabular}{ll} 
Sensor & Definition \\
\hline EXTEROCEPTIVE & $\begin{array}{l}\text { Capture stimuli that are external to the organism (Oxford dictionary), in order to keep him/her aware of the } \\
\text { environmental changes. They are visual (eyes/ophthalmoception), auditory (ears and bones/audioception), } \\
\text { gustatory (tongue with taste buds/gustaoception), olfactory (nose/olfacoception), and somesthetic. The } \\
\text { somesthetic sensors form a complex system able to sense heat or cold (thermoreceptors), pain (nociceptors), } \\
\text { pressure (pacinian corpuscles), and touch (mechanoreceptors) (Amsel 2005). }\end{array}$ \\
\hline PROPRIOCEPTIVE & $\begin{array}{l}\text { Arise from the spatial body orientation. They include the sense of balance (vestibular input from the inner } \\
\text { ear/equilibrioception), position (limb and joint afferents/ stretch receptors), and movement (muscles for } \\
\text { kinesthesioception). }\end{array}$ \\
\hline INTEROCEPTIVE & $\begin{array}{l}\text { Relate to stimuli that are produced within the organism from the visceral, digestive, and autonomic systems to } \\
\text { secure bodily functions. They work through chemoreceptors that regulate hunger, thirst, body temperature, blood } \\
\text { pressure, and sexual behaviour. }\end{array}$ \\
\hline CHRONOCEPTION & $\begin{array}{l}\text { Humans also have limited capabilities to sense of time. However the perception of event duration is subjective } \\
\text { and variable. There is no direct sensor for time, it is mostly reconstructed from other sensed information } \\
\text { (Tangient 2013). }\end{array}$
\end{tabular}

Humans are also capable of cross-sensory transfers. For example people who lose sight can partially substitute the visual sense with enhanced auditory and tactile senses. Furthermore, sensory substitution devices can be employed as a new means to acquire the non-accessible information to compensate for the loss of one sense (Bach-y-Rita and Kercel 2003; Lenay et al. 2003). Synaesthesia is a phenomenon "in which stimulation of one sensory modality causes unusual experiences in a second, unstimulated modality" (Hubbard and Ramachandran 2005) like letters or numbers that are associated with colours (grapheme-colour synaesthesia), sounds that induce colours (Grossenbacher and Lovelace 2001), or lexical-gustatory synaesthesia where sounds evoke a taste (Ward and Simner 2003). Real synaesthesia happens involuntary and concerns about $4 \%$ of the population (Simner et al. 2006).

This is a brief overview on the type of information a human is able to capture. So far, products address only a few of these capabilities. The focus lies on the visual and auditory information and an emerging trend is tactile and olfactory stimuli. Product Design has high potential to address a wide spectrum of sensors. For example, when touch becomes part of design considerations, the texture but also the felt temperature of the material or the weight of the object are dimensions that humans can sense and appreciate.

\section{HUMAN COGNITION \& AFFECT}

Once stimulus information has been captured by the human sensors, it enters the perception of the human preparing responses to this stimulus. The perception involves two closely related mechanisms: cognition and affect. Cognition enables the human to understand the environment, affect allows him/her to judge what $\mathrm{s} / \mathrm{he}$ perceives (Bonnardel 2012). Cognitive events are essentially related to an object/a situation/something. Contrarily, humans experience emotional episodes induced by an object but also independently of any stimulus (Russell 2003). Neuroscientists remain discordant as to whether each are distinct or if cognition is included in the affective process. They do however agree that affect has a cognitive component (Lane et al. 2000; Russell 2003; Scherer 2004; Bonnardel 2012). Khalid (2006) suggests that humans treat stimuli in parallel on the affective and on the cognitive level. Affect is intuitive and experiential. Cognition is the analytical, rational part of information treatment. It creates lasting knowledge and accords meanings.

To understand cognitive and affective mechanisms of human perception is important for Design. Several cognitive and affective components are intentionally or unintentionally addressed by a product or interface. The 
better we understand these mechanisms, the more consciously we can design objects to achieve the desired cognitive and affective response.

Cognitive processes link the external stimuli information with the brain (the user's knowledge and memories) in order to reach an interpretation of the stimuli based on their semantic and aesthetic qualities (Hassenzahl 2003). They also allow for evaluation based on the user's concerns/values/preferences and lead to the prediction, planning, and coordination of outputs (Cariani 2001).

In the beginning, a stimulus holds different types of information on several cases at a specific instance in time (e.g. the current condition of an object property such as the fill level of a glass of water). The information is processed in the following way: when a message/input is received, the human seeks to find an already available interpretation of this case. If that exits, s/he will verify if the new information is in accordance with the old interpretation. If that is the case, this interpretation will be reinforced and the behaviour is equivalent to that following a previous similar experience. This is the quickest cognitive treatment - only going through the socalled 'system 1'. If the new information does not fit well with old interpretations, old knowledge patterns are modified or if no interpretation exists so far, other schemas are sought to help with the interpretation. The socalled system 2 enters a more complex cycle of analysis than system 1 . The human will try one schema after another starting with the schemas that are the easiest to reach / that have served often - because human cognition is lazy. Once s/he finds a satisfying interpretation, s/he will decide for the appropriate response. The applied schema will become more easily accessible. If no schema can be found to interpret the information, no interpretation is done and no response follows (Axelrod 1973; Kahneman 2012).

Contrary to cognitive processes, the affective part of information processing is still little understood and models are more based on folklore than on scientific concepts (Russell 2003). Some researchers call it affects, others emotions. Yet emotions are only one part of affects. Wundt was the first to propose an affect model. It is based on three continuous dimensions: pleasant-unpleasant (valence), tension-relaxation (tension) and excitement-calm (arousal) (Wundt 1914). Studies suggest that unpleasant stimuli are more arousing than pleasant ones (Bradley and Lang 2000). It has also been shown that events that are accompanied by strong arousal are better remembered. However this seems to be stronger for negative than for positive valence (Kensinger 2009). As a synthesis of the types of affects defined by Scherer (2004) and Russell (2003), Table 2 gathers types of human affects that can be distinguished:

Table 2: Types of human affects.

\begin{tabular}{ll} 
Affect type & Definition \\
\hline CORE AFFECT (MOOD) & $\begin{array}{l}\text { Diffuse affect states of low intensity, usually rather long lasting, independent of an object/person/event (irritable, } \\
\text { depressed, cheerful, buoyant, etc.). }\end{array}$ \\
\hline ATTRIBUTED AFFECT & Affect attributed to an object/person/event. \\
\cline { 2 - 2 } UTILITARIAN EMOTIONS & $\begin{array}{l}\text { Brief episodes of synchronised response "of all or most of the five organismic subsystems" to an external or } \\
\text { internal stimulus event that is relevant to the organism, personal goals and bodily needs (fear, anger, sadness, joy, } \\
\text { disgust, etc.). }\end{array}$ \\
\cline { 2 - 3 } AESTHETIC EMOTIONS & $\begin{array}{l}\text { Brief episodes experienced through evaluations of sensorial stimuli on their intrinsic qualities, irrespective of } \\
\text { bodily needs, current goals or social concerns, addressed to a cause like a piece of art, a design, music, etc. (being } \\
\text { full of wonder, admiration, fascination, ecstasy, harmony, rapture, etc.). }\end{array}$ \\
\hline PREFERENCES & Stable evaluative judgements on the pleasantness of a stimulus (like/dislike, positive/negative). \\
\hline CONCERNS/VALUES & $\begin{array}{l}\text { Enduring beliefs or predispositions towards an object or a person (loving, hating, desiring, rejecting, etc.). They } \\
\text { are based on values that are "desirable, trans-situational goals [...] that serve as guiding principles in people's } \\
\text { lives" (Schwartz and Sagiv 1995). }\end{array}$ \\
\hline AFFECT DisPOSITIONS & $\begin{array}{l}\text { Stable personality traits that lead a person to frequently experience certain moods and to react with similar } \\
\text { emotions and behaviours to certain types of objects, persons or events (nervous, anxious, reckless, jealous, etc.). }\end{array}$
\end{tabular}

Affect dispositions, concerns/values and preferences are rather stable elements of human affect. They slowly evolve over the person's lifetime as a result of interaction with the environment (Desmet and Hekkert 2007). Core affect can last for a day, some days or even weeks. Attributed affect alters instantly with each new stimulus. There are long-lasting affect components that influence the experienced temporary core affect and attributed affect. As such affect dispositions, concerns/values and preferences are always present, but only addressed once there is an external stimulus to be evaluated. Contrary to this, humans always experience some state of core affect, even if they are not conscious of it. Core affect is an intrinsic state of the human. It describes a mood or a lasting state. At any one time anybody is able to define his/her core affect state.

Products can be an external cause that alters core affect (Russell 2003). When the human perceives an external stimulus, an emotional episode starts. Emotional episodes are evoked by the affective quality of the stimulus, which can be perceived as pleasant or unpleasant, and activating or deactivating. The perception of the affective quality of a stimulus does not necessarily change the core affect. Both can be experienced at the same time even in a non-congruent way. Somebody who feels depressed will find a joke funny, and still feel sad. An affective quality that is perceived by the human becomes an attributed affect (Russell 2003). Scherer's utilitarian and aesthetic emotions can be considered as two different types of attributed affect. 
Design evaluations should try to distinguish between attributed affects and core affects in order to draw relevant conclusions. People are able to evaluate the affective quality of objects or events even without being in the real situation (Russell 2003). However, core affects can only be measured in the real interaction. Otherwise there is the risk of misinterpretation caused by misattribution or mood-congruent judgement. Misattribution means that the core affects evoked by one source is mistakenly attributed to the wrong object (Schwarz and Clore 1983). Mood-congruent judgement has the effect that a person who is feeling happy processes more positive information of the stimulus and therefore rates it more positively than she would if she was in a gloomy mood (Bower and Forgas 2012). Negative moods are more easily attributed to an external cause than positive moods (Schwarz and Clore 1983).

To evaluate the affective quality of a product, it might therefore be useful to first measure the core affect of the test person, and then the quality the person attributes to the product. When we downgrade the attributed affects for persons with a highly positive core affects and upgrade it for those with a negative core affects we might get an overall idea of the actual affective quality of the product. It is also relevant to understand the values, preferences and disposition of a person to interpret her evaluation of a design (Bouchard et al. 2009).

Now that we have seen human sensors and cognitive and affective treatment of stimulus information, let us take a look at the responding side of human perception.

\section{HUMAN RESPONSES}

Human responses constitute the third element of the human percept-action loop. There are three different response types: physiological/somatic, motor, motivational (Scherer 2004; Scherer 2005). Motor and motivational responses are related to controllable events. Physiological responses can also be of uncontrollable nature (see Table 3).

Table 3: Types of human responses.

\section{Response type Definition}

PHYSIOLOGICAL EFFECTS Responses of the human metabolism. Symptoms are temperature sensations as a consequence of blood bodily symptoms circulation (red cheeks, cold hands, pale face), respiratory accelerations/decelerations, cardiovascular accelerations/decelerations, muscle tension (weak limbs, trembling, relaxing), constriction in internal organs (stomach ache, lump in the throat), and body fluids (transpiration, salvia, odorant) (Scherer 2004). These responses happen when events appear that disturb the on-going body state. They have for purpose to set the human body in the condition necessary to cope with the situation. An augmented blood rate for example prepares the body to run away from an aggressor. They can also be an unconscious means of communication.

MOTOR EFFECTS Occur on three different body parts: the limbs (gestural, postural), the face (mimic), and the speech organs facial, gestural, posture, (vocal). Gestures, postures, mimics and voice are more or less controllable means of human $\operatorname{vocal}($ action) communication that enable him/her to visually and audibly show the outsider in which state the situation put him/her and how s/he will react (Scherer 2004). Values that distinguish motor effects are the speed, the amplitude, the frequency/rhythm, pauses, and patterns. The meanings of facial expressions have been subject of research in psychology from Darwin, to Paul Ekman, and Nico H. Frijda.

\begin{tabular}{ll}
\hline MOTIVATIONAL EFFECTS \\
$\begin{array}{l}\text { action tendencies and } \\
\text { readiness (behaviour) }\end{array}$
\end{tabular} $\begin{aligned} & \text { Stable action tendencies towards a specific object or situation (Scherer 2005), in general approach or } \\
& \text { withdrawal (Russell 2003). Become visible in human comportment. The person directs her attention to the } \\
& \text { subject, like somebody who always buys a specific brand or acts with consciousness on the environmental } \\
& \text { impact of his/her behaviour. }\end{aligned}$

Responses that users show to products can be observed or measured with techniques such as eye tracking or with physiological measurements such as EEG (electroencephalogram) or GSR(galvanic skin response) (Kim 2011). They provide relatively objective data to researchers. However, even though these responses are the result of cognitive and affective judgements, "no specific action or action tendency is produced by or is necessary for a specific emotion" (Russell 2003). That means an observed behaviour does not represent one specific affect felt by the person. It is still necessary to look at the totality of responses and the person's subjective self-evaluations in order to draw conclusions on his/her experience.

This first part introduced the dimensions of human perception. We saw that humans draw upon a wide range of sensors to capture stimulus information. Here lies a first entry point for original ideas to design for UX. We also talked about the manner in which stimulus information is processed through the interplay of human cognition and affect. To address certain cognitive responses, designers can work on a semantic expression of a product. Designs can also transport a certain affective quality. But the designer cannot control all individual dimensions of human perception. A person's current mood or previous memories are outside of the design scope. Nevertheless, this points at a huge potential for intelligent products that can adapt their properties to the user's individual affective disposition and knowledge. Finally, we saw the range of human responses. They can be of physiological, behavioural or motivational nature. A design that causes reactions on each of these three levels is likely to be more engaging than one that only addresses one level. Product developers should envision ways to enable their products to not only react on behavioural but also on physiological responses. In order to 
do so, the designer needs to know which product dimensions s/he can potentially influence through his/her design. This is therefore the topic of the next section.

\section{DIMENSIONS OF PRODUCTS}

A product is a specific type of object or interface or service that serves a certain purpose and that can be classed in a certain sector such as automobile, food, cosmetics, etc. (Krippendorff 2005). Hassenzahl (2003) assigns four major functions to products: 1. Enable people to manipulate their environment, 2. Stimulate personal development, 3. Express identity, and 4. Evoke memories. To do so, products must possess certain properties that facilitate these functions. Classical dimensions of Product Design are functionalities, semantics, form, colour, material, texture etc. They will not be further discussed here since it seems more interesting to look at properties that enable the product to interact with the environment or the user. Today products too come with sensors that facilitate intelligent responses to user responses. Some product properties can also be designed with their own dynamic behaviour. An analogy can therefore be drawn with the human perceptive system. In the following, potential sensory and responsive capabilities of products will be presented.

\section{PRODUCT SENSORS}

In order to react to user inputs, products need to be capable of perceiving human responses. Classic consumer products (furniture or decoration, or the external parts of industrial designs like car chassis, telephone housing, etc.) are usually not equipped with sensors. Nowadays there are more and more products that show a dynamic reaction to user inputs through tangible or graphic user interfaces. These products come equipped with a great variety of sensors that can be classified into the types listed in Table 4 (Robotworx 2013):

Table 4: Types of sensors for consumer products.

\begin{tabular}{lll} 
Sensors categories & Sensors types & Definition \\
\hline PHYSICAL SENSORS & Active sensors & Emit some form of energy - ultrasonic, laser, infrared \\
\cline { 2 - 3 } & Passive sensors & $\begin{array}{l}\text { Receive energy } \\
\text { Example: a camera }\end{array}$ \\
\hline LOGICAL SENSORS & Supply robot with a percept from the physical sensor \\
\hline PROPRIOCEPTIVE SENSORS & $\begin{array}{l}\text { Monitor self-maintenance, control internal status } \\
\text { Examples: Global Positioning System (GPS), Inertial Navigation } \\
\text { System (INS), Shaft/rotary Encoder, Compass, Inclinometer }\end{array}$ \\
\hline & Contact Sensors & $\begin{array}{l}\text { Emit a signal on physical contact } \\
\text { Measure the interaction force and torque } \\
\text { Tactile sensors, conductivity } \\
\text { (linear, circular, discontinued) }\end{array}$ \\
\cline { 2 - 3 } & Range Sensors & $\begin{array}{l}\text { Measure distance to an object } \\
\text { Two principles: time-of-flight and triangulation } \\
\text { (reflection, sonar, capacity) }\end{array}$ \\
& Extract, characterize and interpret visual information \\
\cline { 2 - 3 } & Vision Sensors & $\begin{array}{l}\text { Combine proprioceptive and exteroceptive monitoring } \\
\text { to measure the relative position through directional sensors, to measure } \\
\text { difference between internal and external heart; } \\
\text { Examples: panning sonar sensors, force sensors }\end{array}$ \\
\hline EXPROPRIOCEPTIVE SENSORS & & Measure torque or force or weight
\end{tabular}

Today Product Designers have access to a wide range of sensors and actuators (for behavioural response) that are easy to employ in the phases of rapid prototyping - nearly like a pen for sketching or some 3D software for modelling. There are for example the Arduino kits (Arduino 2012) or Phidgets (Phidgets 2012) with MAX/MSP, Processing or Adobe Flash with ActionScript that allow designers to model interactive behaviour coupled with sensing technology. These techniques find their way into design education and once design graduates master them, they will enrich the interactivity of products and with it the UX (Helm, Aprile, and Keyson 2008).

\section{PRODUCT RESPONSES}

All externally perceivable product dimensions are potential stimuli for the user. Products can be characterised through concrete dimensions of lower order and abstract dimensions of higher order (Snelders 2003).

Concrete dimensions include the properties of functional, behavioural, semantic and sensorial properties. They are designed to evoke abstract dimensions on a pragmatic and a hedonic level (Hassenzahl 2003). The term 'pragmatic' refers to the product utility and usability. A product with a strong pragmatic quality simply fulfils a functional purpose, e.g. using a pair of scissors to cut paper. The hedonic side addresses the user emotions, values, and memories. A product with a strong hedonic quality, such as a family photo, might have no pragmatic quality but can be very valuable to the person. While the perception of abstract properties might differ strongly between users, the perception of concrete properties is essentially the same between people of different 
backgrounds. In user-centred design, abstract properties define the design objective. The Product Designer then materialises this objective through the concrete properties (Snelders 2003).

Classical Product Designs stimulate the user through function and appearance/semantics. Since intelligent technologies have found their way into consumer products, more and more products are connected to a network, are pro-active and capable of adaption to events (Ross and Wensveen 2010). The design of intelligent products goes beyond traditional Product Design and can even be independent of physical materials (Lim, Lee, and Lee 2009). To conceive interactive products, designers require "a new language of form that incorporates the dynamics of behavior" (Ross and Wensveen 2010).

Dynamic product responses mean that the product adapts its properties to the situation. It may for example alter the orientation of some of its components (like Nabaztag moving his ears) or its colour (e.g. clicked links). These changes can be instantaneous or follow a fixed pattern (Lim, Lee, and Lee 2009; Lin and Cheng 2011). Shape change is a specific behaviour that waits to be exploited by Product Designers. Examples are changes of orientation, form, volume, texture, viscosity, spatial changes, as well as addition or subtraction of elements or changes of permeability (Kirkegaard Rasmussen et al. 2012). Related to it are spatial distribution and motion patterns that can express complex meanings that people interpret on a social dimension (approaching, avoiding, etc.) (Mutlu et al. 2006). Other examples of dynamic product responses can be seen in Table 5.

Table 5: Possible dynamic responses of products.

\begin{tabular}{|c|c|c|}
\hline Dimension & Property & Behaviour \\
\hline Material & (Depending on the material) & Elasticity, colour, temperature, conductivity...(Ashby and Johnson 2010) \\
\hline Colour & & Hue, saturation, lightness \\
\hline Texture & $\begin{array}{l}\text { Visual texture } \\
\text { Tactile texture }\end{array}$ & $\begin{array}{l}\text { Transparency... } \\
\text { Smoothness... }\end{array}$ \\
\hline Illumination & & Intensity, colour, movement pattern, fade pattern \\
\hline \multirow{5}{*}{$\begin{array}{l}\text { Sound } \\
\text { (Özcan 2008) }\end{array}$} & Volume & Increase or decrease \\
\hline & Timbre & Change type \\
\hline & Pitch & Increase or decrease \\
\hline & Melody / pattern & Change in a pattern or randomly \\
\hline & Spatiality (source) & Orientation change \\
\hline \multirow[t]{2}{*}{ Form } & & $\begin{array}{l}\text { Geometrically defined } \\
\text { Free-forms } \\
\text { Adapt to human dimensions (ergonomic) }\end{array}$ \\
\hline & Body volume & Increase or decrease \\
\hline Orientation & & $\begin{array}{l}\text { Between two states or seamlessly } \\
360^{\circ} \text {, on } 3 \text { spatial axes }\end{array}$ \\
\hline Permeability & & $\begin{array}{l}\text { Binary or seamlessly } \\
\text { From complete permeability to impermeable }\end{array}$ \\
\hline $\begin{array}{l}\text { Spatial } \\
\text { distribution }\end{array}$ & & $\begin{array}{l}\text { of product elements in the available space systematic (meaningful) } \\
\text { or random way; } \\
\text { the product itself can change its position in the room/space }\end{array}$ \\
\hline Components & & Can be added/subtracted \\
\hline Functionality & & $\begin{array}{l}\text { Can change when the purpose is distorted, e.g. a bottle becomes a vase, a chair used as a } \\
\text { ladder }\end{array}$ \\
\hline Language style & & $\begin{array}{l}\text { Casual / formal style } \\
\text { Natural / artificial style (Blanchy 2010) }\end{array}$ \\
\hline
\end{tabular}

Products are formed by a wide range of design dimensions. They define the product appearance as well as its behaviour. To this day Product Design is often seen as something static. But products can be equipped for dynamic responses. Designers have the possibility to explore, for example, form changes thanks to flexible materials, or spatiality and motion changes on graphic interfaces in order to communicate with the user or to adapt the behaviour to the context of use. To design such adaptive behaviour, Product Designers require knowledge about the different types of human or environmental responses that a product can capture if equipped with the corresponding sensors and they should exploit the possibilities of the here presented response types.

\section{DIMENSIONS OF THE CONTEXT OF USE}

Any UX is embedded in a specific interaction situation. The context of use also influences which properties the human or product sensors will capture. It might furthermore influence the treatment of the stimulus information. The externalities of the context of use that influence UX are situational, cultural, and social dimensions (Forlizzi and Ford 2000; Crilly, Moultrie, and Clarkson 2004; Krippendorff 2005; Locher, Overbeeke, and Wensveen 2009; Robert and Lesage 2011). Table 6 provides an overview of potential context dimensions: 
Table 6: Dimensions of the context of use.

\begin{tabular}{ll}
\hline Situational dimensions & Viewing time \\
\cline { 2 - 2 } & Related products/features/things \\
& Place \\
\hline Time \\
\hline Cultural dimensions/references & Event/activity \\
\cline { 2 - 2 } & Similar products/brands/activities \\
\cline { 2 - 2 } Social dimensions & Trends/fareotypes \\
\hline
\end{tabular}

\section{THE TEMPORAL DIMENSION OF EXPERIENCE}

Last but not least, time is another important UX dimension. Some experiences such as a surprise can only be lived once while other experiences grow over various use episodes. Hassenzahl (2010) demands a "longitudinal approach" when designing for UX. He distinguishes between a micro (an hour of usage), meso (a few weeks of usage), and macro (years of usage) perspective on the UX with a product. Roto et al. identified four types of UX over time: the anticipated UX (before usage), the momentary UX (during usage), the episodic UX (after usage), and the cumulative UX (multiple use situations over time) (Roto et al. 2011). From the Product Design point of view, there are two different types of temporality that can be effectively shaped by the designer: The interaction sequence and certain aspects of the cumulative UX.

Interaction sequences: A dynamically changing product is conceived as a continuous cycle of sensing and response on the human and on the product side. The human as well as the artefact are both capable of sensing input, processing this data, and responding with distinct behaviour (output actions). The data circulates between the user and the product and is transformed (Krippendorff 2005). The emotions felt by the user change over the different interaction sequences (Lin and Cheng 2011).

Long-term UX: An interactive product might show reoccurring response patterns to user actions, but the user might respond differently after a while. Surprise can only be triggered once. Excitement changes into comfort once the user gets familiar with the product. Even when the product disappears from his/her sight, the memory of it can still trigger emotions (Norman 2004). Karapanos et al. (2009) studied the experience of iPhone users from the intention of purchase, until after a few months of usage. They proved a shift in UX over time. During the initial orientation phase, the experience is mainly formed by stimulation and learnability. This leads to a certain familiarity with the product. In the following incorporation phase usefulness and long-term usability are important. A functional dependency of the user on the product appears. Finally the user can enter the phase of identification where s/he shows an emotional attachment to the product.

Designers should anticipate the course of UX over interaction sequences as well as the evolvement of UX over the time of product use during their design process.

\section{CONCLUSION: FROM PRODUCT DESIGN TO DESIGN FOR UX}

For centuries, people have created and refined products. A common understanding of Gestalt laws or colour harmonies has developed within and beyond cultural borders. In the past, engineers dealt with functions, components and performance; while Product Designers were asked to work on form, colour, and semantic (Djajadiningrat et al. 2004). Now microcontrollers have considerably enriched the capabilities of everyday products to process the user input and to respond with discrete output behaviour (Lim and Kim 2011) and therefore, to adapt their behaviour to the context of use and user actions/responses (Djajadiningrat et al. 2004).

This brings new opportunities as well as challenges to Product Designers. The user perception of interactive products goes far beyond form-giving. Interaction impacts the affective experience (Schuster Smith 2008). Hassenzahl illustrates this with the example of the Philips Wake-Up Light: “...it substantially changes the way one wakes up. It changes the experience. The object itself, its form, is rather unremarkable" (Hassenzahl, Eckoldt, and Thielsch 2009).

Even though people might not expect great emotional stimulation from all products, it cannot be neglected that each artefact causes a reaction in its user - appeal, indifference or rejection. Thus, all goods and services made for consumers have to respond to some kind of physiological, psychological or social human need (Lim 2003). Today form-giving is only one part of Product Design. 


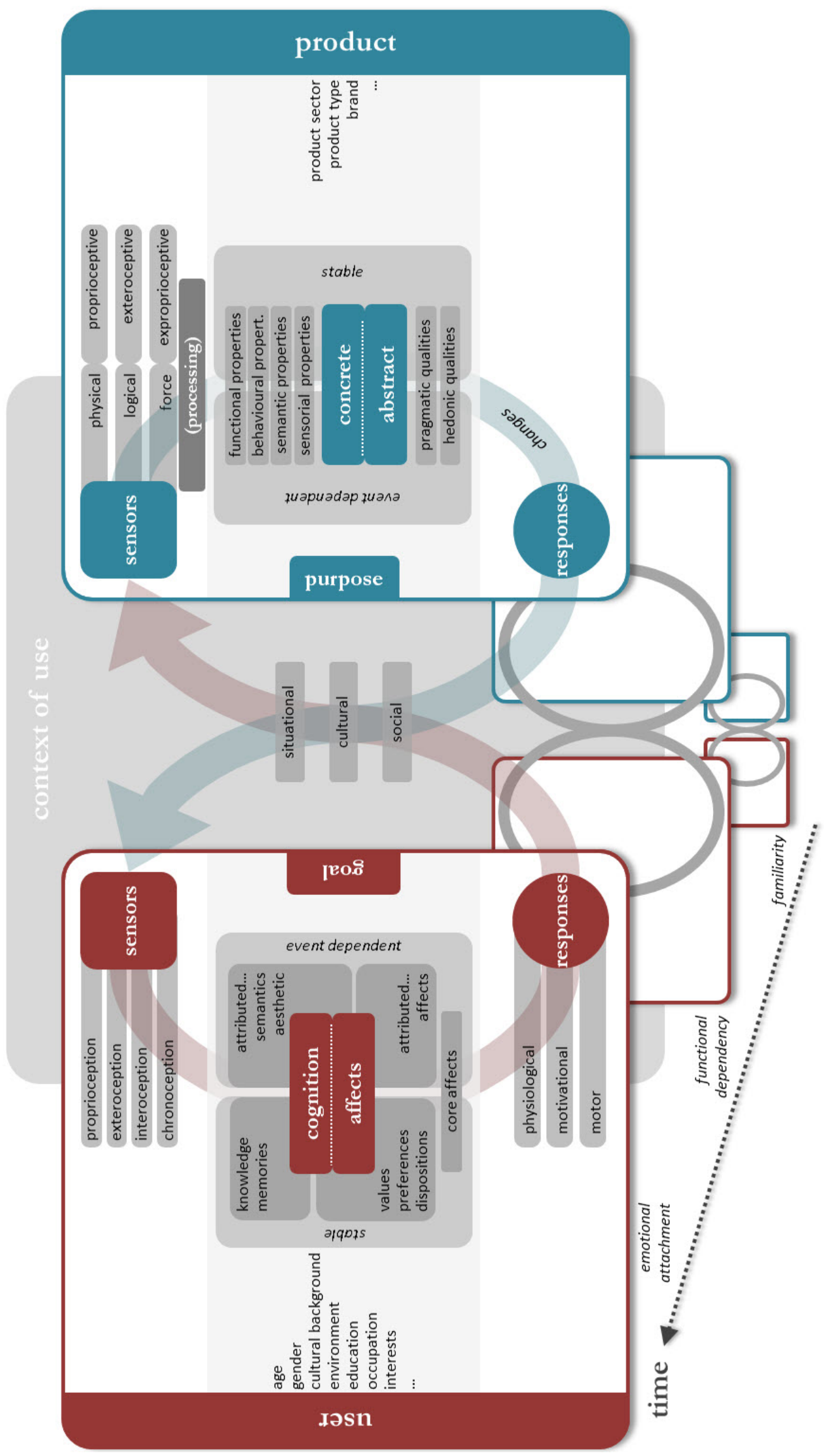

Figure 3: Schéma of dimensions of the User-Product Experience. 
Through this literature review, we have sought to demonstrate how UX results from the interplay of a wide range of concrete (form, colour, semantic, function) and abstract (affective and sensorial quality, semantic quality, aesthetic quality) product dimensions, together with their perception by the target user, the context in which $\mathrm{s} /$ he encounters the product and the temporality of the experience (see Figure 3 ).

Today the challenge for Product Designers is to adopt a holistic view of UX during conceptual design and design evaluation. That means, conceptual design should always target congruence between identified (and potentially evolving) user goals and the product purpose. The Product Designer defines function, semantic, sensorial and behavioural properties with regard to their hedonic and pragmatic quality. To validate and improve the designed experience, concepts and prototypes should then be regularly evaluated through user tests. These evaluations verify which pragmatic and hedonic qualities the user really attributes to the designed product (Figure 4).
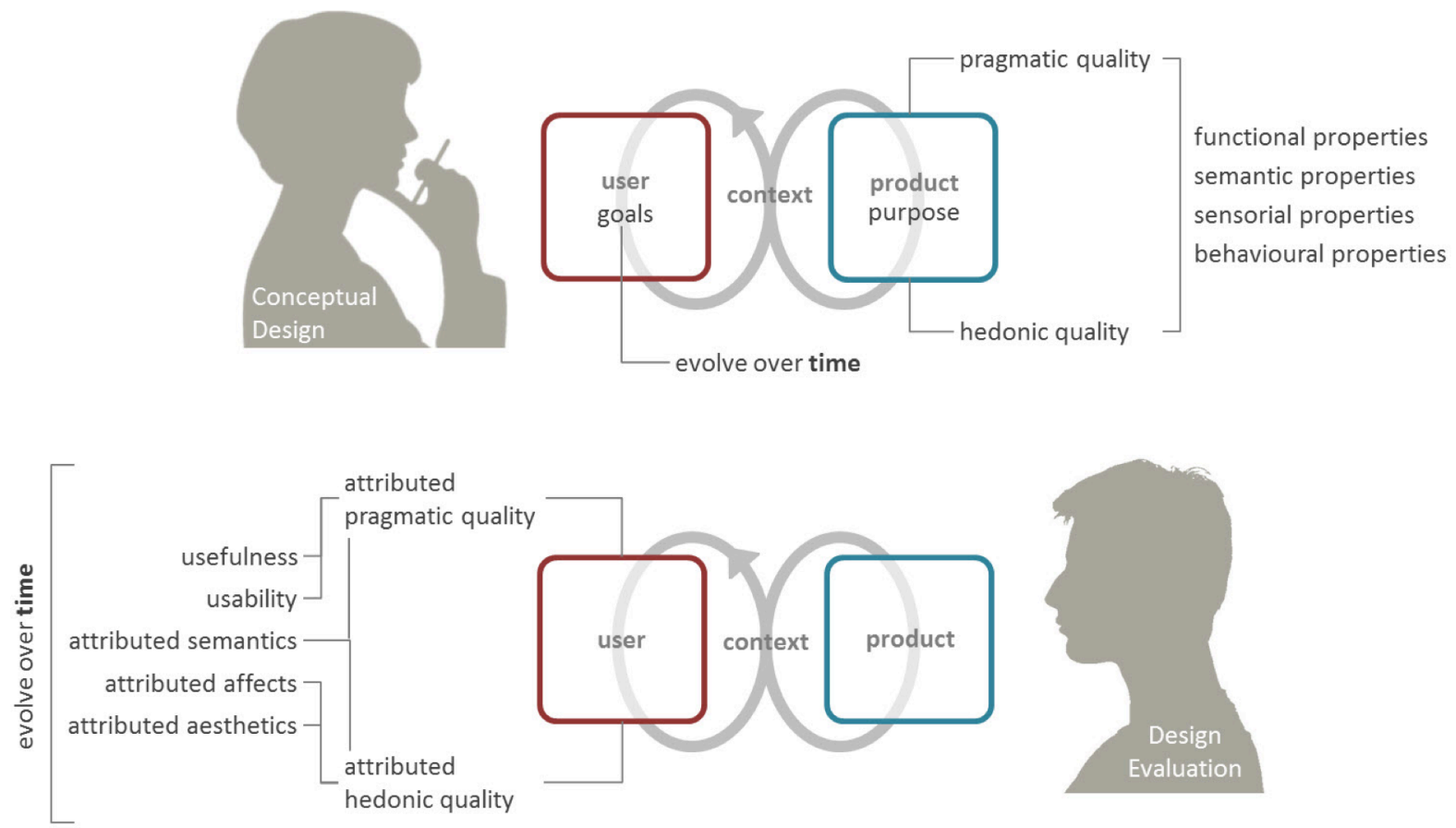

Figure 4: Dimensions of conceptual design (top) and design evaluation (bottom) when designing for UX.

\section{ACKNOWLEDGEMENT}

This literature review is part of a thesis undertaken in the context of the ANR project Skippi. We thank the Agence Nationale de la Recherche for its financial and pedagogical support.

\section{REFERENCES}

AMSEL, S. 2005. “Special Senses.' Touch. Exploring Nature Educational Resource.” http://exploringnature.org/db/detail.php?dbID=25\&detID $=47$.

ARDUINO. 2012. "Arduino." http://www.arduino.cc/.

AshBY, M. F., and Johnson, K. 2010. Materials and Design. Oxford: Butterworth-Heinemann.

AXELROD, R. 1973. "Schema Theory: An Information Processing Model of Perception and Cognition." The American Political Science Review 67 (4): 1248-1266.

BACH-Y-RitA, P., AND KeRCEL, S. W. 2003. "Sensory Substitution and the Human-machine Interface." Trends in Cognitive Sciences 7 (12) (December): 541-546.

Bargas-Avila, J. A., and HornbeK, K. 2011. "Old Wine in New Bottles or Novel Challenges: A Critical Analysis of Empirical Studies of UX." In Conference on Human Factors in Computing Systems, 2689-2698.

Blanchy, K. 2010. "Interface Design Based on the Philosophy of Japanese Hospitality." In Design and Emotion. Chicago. 
BONNARDEL, N. 2012. "Cognition and Emotion in Creative Design.” In Attention, Representation, and Human Performance: Integration of Cognition, Emotion, and Motivation, edited by S. Masmoudi, A. Naceur, and D. Yun Dai, 187-200. London: Psychology Press.

Bouchard, C., Mantelet, F., Aoussat, A., Solves C., Gonzalez J., Pearce, K., Lottum C., and Coleman, S. 2009. "A European Emotional Investigation in the Field of Shoe Design." International Journal of product Development 7 (1): 3-27.

Bower, G. H., and Forgas, J. P. 2012. "Mood and Social Memory." In Handbook of Affect and Social Cognition, 97-121. Taylor \& Francis.

Bradley, M. M., and LANG, P. J. 2000. "Measuring Emotion: Behavior, Feeling, and Physiology." In Cognitive Neuroscience of Emotion, 242-276. New York: Oxford University Press.

CARIANI, P. 2001. "Symbols and Dynamics in the Brain." Bio Systems 60 (1-3): 59-83.

Crilly, N., Moultrie, J., and Clarkson, P. J. 2004. "Seeing Things: Consumer Response to the Visual Domain in Product Design." Design Studies 25 (6): 547-577.

DeSMet, P. 2002. "Designing Emotions". PhD thesis. TU Delft.

Desmet, P., and HeKkeRT, P. 2007. "Framework of product Experience." International Journal of Design 1: 57-66.

Djajadiningrat, T., Wensveen, S., Frens, J., and Overbeeke, K. 2004. "Tangible products: Redressing the Balance between Appearance and Action." Personal and Ubiquitous Computing 8 (5) (July 31): $294-309$.

ForlizZI, J., and Ford, S. 2000. "The Building Blocks of Experience: An Early Framework for Interaction Designers." In Symposium on Designing Interactive Systems, 419-423. New York, New York, USA.

GiBson, J. J. 1986. The Ecological Approach to Visual Perception. Tayler \& F. New York, New York, USA: Psychology Press.

Green, W., Jordan, P. W. 1999. Human Factors in Product Design: Current Practice and Future Trends. London: Tayler and Francis.

Grossenbacher, P G., and Lovelace C. T. 2001. "Mechanisms of Synesthesia: Cognitive and Physiological Constraints." Trends in Cognitive Sciences 5 (1) (January 1): 36-41.

HASSEnZAHL, M. 2003. "The Thing and I: Understanding the Relationship Between User and product." In Funology: From Usability to Enjoyment, edited by M. A. Blythe, K. Overbeeke, A. F. Monk, and P. C. Wright, 31-42. Dordrecht: Kluwer Academic Publishers.

Hassenzahl, M. 2010. Experience Design - Technology for All the Right Reasons. Edited by John Caroll. Morgan \& Claypool.

HASSENZAHL, M. 2011. “UX and Experience Design.” In Encyclopedia of Human-Computer Interaction, edited by Mads Soegaard and Rikke Friis Dam. Aarhus, Denmark: The Interaction Design Foundation. http://www.interaction-design.org/encyclopedia/user_experience_and_experience_design.html.

Hassenzahl, M., EcKOldt, K. and Thielsch, M. T. 2009. "UX Ū Und Experience Design - Konzepte Und Herausforderungen." In Usability Professionals 2009. Berichtband Des Siebten Workshops Des German Chapters Der Usability Professionals Association e.V., edited by H. Brau, 233-237. Stuttgart: FraunhoferVerlag.

Helm, A. VAn Der, Aprile, W. and KeYson, D. 2008. "Experience Design for Interactive products : Designing Technology Augmented Urban Playgrounds for Girls." PsychNology 6 (2): 173-188.

Hubbard, E. M., and RAmaChandRAn, V. S. 2005. "Neurocognitive Mechanisms of Synesthesia." Neuron 48 (3) (November 3): 509-20.

Kahneman, D. 2012. Thinking, Fast and Slow. London: Penguin Books.

Karapanos, E., Zimmerman, J., Forlizzi, J., and Martens, J.-B. 2009. "UX over Time: An Initial Framework." In Conference on Human Factors in Computing Systems. Boston, Massachusetts.

KENSINGER, E. A. 2009. "Remembering the Details: Effects of Emotion." Emotion Review: Journal of the International Society for Research on Emotion 1 (2) (January): 99-113.

KHALID, H. M. 2006. "Embracing Diversity in User Needs for Affective Design.” Applied Ergonomics 37 (4) (July): 409-18.

KIM, J. 2011. "Modeling Cognitive and Affective Processes of Designers in the Early Stages of Design: Mental Categorization of Information Processing." PhD thesis. Arts \& Métiers ParisTech.

Kirkegaard Rasmussen, M., Pedersen, E. W., Petersen, M. G., and Hornbæk, K. 2012. "Shape-Changing Interfaces: A Review of the Design Space and Open Research Questions." In Conference on Human Factors in Computing Systems, 1-10. Austin, Texas.

KrIPPENDORFF, K. 2005. The Semantic Turn: A New Foundation for Design. Boca Ratan, London, New York: CRC Press.

LAMuth, J. E. 2011. "Input Specificity - Exteroceptive, Interoceptive, and Proprioceptive." http://www.angelfire.com/rnb/fairhaven/inputspecificity.html. 
Lane, R. D., Nadel, L., Allen, J. J. B. and Kaszniak, A. W. 2000. "The Study of Emotion from the Perspective of Cognitive Neuroscience." In Cognitive Neuroscience of Emotion, 3-11. New York: Oxford University Press.

LENAY, C. 2006. "Énaction, Externalisme et Suppléance Perceptive.” Intellectica 1 (43): 27-52.

Lenay, C., Gapenne, O., Hanneton, S., Marque, C., and GenouëLle, C. 2003. "Sensory Substitution: Limits and Perspectives." In Touching for Knowing, edited by Yvette Hatwell, Arlette Streri, and Edouard Gentaz, 275-290. Paris: John Benjamins B.V.

LiM, D. 2003. "Modelisation Du Processus de Conception Centrée Utilisateur, Basée Sur L’intégration Des Méthodes et Outils de L'ergonomie Cognitive: Application À La Conception d'IHM Pour La Télévision Interactive." PhD thesis. Arts \& Métiers ParisTech.

LIM, Y., and KIM, D.-J. 2011. "Interactivity Attributes for Expression-Oriented Interaction Design." International Journal of Design 5 (3): 113-128.

LiM, Y., LEE, S.-S., and LEE, K.-Y. 2009. "Interactivity Attributes: A New Way of Thinking and Describing Interactivity." In Conference on Human Factors in Computing Systems, 105-108. Boston.

LIN, M.-H., and CHENG, S.-H. 2011. "Semantic Shifting within the Interaction Sequence." In IASDR, 1-10. Delft.

Locher, P., Overbeeke, K. and Wensveen, S. 2009. “A Framework for Aesthetic Experience.” In Conference on Human Factors in Computing Systems. Boston.

Mutlu, B., Forlizzi, J., NourbaKhSh, I., and Hodgins, J. 2006. "The Use of Abstraction and Motion in the Design of Social Interfaces." In DIS. Pennsylvania.

Norman, D. A. 2004. The Design of Everyday Things. New York: Basic Books.

Norman, D. A. 2004. Emotional Design. Cambridge, MA: Basic Books.

Özcan, E. 2008. "Product Sounds". PhD thesis. TU Delft.

PHIDGETS, Inc. 2012. "Phidgets." http://www.phidgets.com/.

RoBert, J.-M., Lesage, A. 2011. "Designing and evaluating user experience." In Handbook of HumanComputer Interaction. A human-centered design approach, edited by G.A. Boy, 321-338. Surrey, UK: Ashgate Publishing Limited.

RoBOTwORX. 2013. "Robot Sensors." Accessed February 5. http://www.robots.com/education/exteroceptivesensors.

Ross, P. R., and Wensveen, S. A. G. 2010. "Designing Behavior in Interaction: Using Aesthetic Experience as a Mechanism for Design." International Journal of Design 4 (2): 3-13.

Roto, V., Law, E., Vermeeren, A., and Hoonhout, J. 2011. "UX White Paper: Bringing Clarity to the Concept of UX.” Seminar. Dagstuhl, Germany.

Russell, J. A. 2003. "Core Affect and the Psychological Construction of Emotion." Psychological Review 110 (1): $145-172$.

Salvia, G., Rognoli, V., Malvoni, E., and Levi, M. 2010. “The Objectivity of Users' Emotional Experience with Textiles Biological and Mechanical Tests for the Prediction of the Sensorial Profile of Fabrics." In Seventh International Conference on Design and Emotion, 1-12. Chicago, IL.

SCHERER, K. R. 2004. "Which Emotions Can Be Induced by Music? What Are the Underlying Mechanisms? And How Can We Measure Them?” Journal of New Music Research 33 (3) (September): 239-251.

SCHERER, K. R. 2005. "What Are Emotions? And How Can They Be Measured?" Social Science Information 44 (4) (December): 695-729.

SChifferstein, H.N.J., HeKKert, P. (Eds.) 2008. Product Experience. Elsevier Science.

SCHUSTER Smith, H. 2008. "Emotional Evaluation of a product/System". PhD thesis. University of Central Florida.

Schwartz, S. H., and SAgiv, L. 1995. "Identifying Culture-Specifics in the Content and Structure of Values." Journal of Cross-Cultural Psychology 26 (1) (January 1): 92-116.

SCHWARZ, N., and ClORE, G. L. 1983. "Mood, Misattribution, and Judgements of Well-Being: Informative and Directive Functions of Affective States.” Journal of Personality and Social Psychology 45 (3): 513-523.

Simner, J., Mulvenna, C., Sagiv, N., Tsakanikos, E., Witherby, S. A., Fraser, C., Scott, K., and Ward, J. 2006. "Synaesthesia: The Prevalence of Atypical Cross-Modal Experiences." Perception 35 (8): 1024-1033.

SNELDERS, D. 2003. "An Exploratory Study of the Relation between Concrete and Abstract product Attributes." Journal of Economic Psychology 25 (December): 803-820.

TANGIENT LLC. 2013. "Chronoception.” http://scalometer.wikispaces.com/chronoception.

Tomico, O., Mizutani, N., Levy, P., TAKAhiro, Y., and ChO, Y. 2008. "Kansei Physiological Measurements and Constructivist Psychological Explorations for Approaching User Subjective Experience During and After product Usage.” In International Design Conference - Design, 529-536. Dubrovnik.

WARD, J., and Simner, J. 2003. "Lexical-Gustatory Synaesthesia: Linguistic and Conceptual Factors." Cognition 89 (3) (October): 237-261.

WundT, W. M. 1914. Grundriss Der Psychology. Edited by Jazzybee Verlag. 
Kerstin Bongard-Blanchy is a UX designer und researcher. During her $\mathrm{PhD}$ thesis at the Product Design and Innovation Laboratory, Arts et Métiers ParisTech, France she investigated ideation and evaluation tools for UX Design (2010-2013). Following her studies of mechanical engineering/industrial design at Dresden University of Technology, Germany (2006), she had worked as Interaction Designer for Panasonic in Japan (2006-2010) where she designed mobile phone interfaces, product sounds and lights as interaction means. She currently develops and tests user interfaces for Dassault Systèmes.

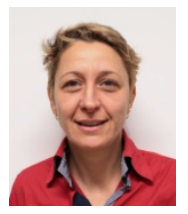

Carole Bouchard is professor at Arts et Métiers, ParisTech, France. She teaches and guides research in the Product Design and Innovation Laboratory. She obtained her PhD in industrial engineering in 1997 in the field of automotive design and has been professor since 2012. Her research focus is on Kansei Design, as well as creativity and innovation in early design stages. She pilots various research projects that seek to develop innovative design tools to efficiently integrate Kansei principles into the design process. Current projects include user-centred Eco Design methods, a word-based conception software for multidisciplinary teams and the development of an immersive spatialized design workspace. 